\title{
Exposure to secondhand smoke and voluntary adoption of smoke-free home and car rules among non-smoking South African adults
}

\author{
Olalekan A Ayo-Yusuf ${ }^{1,2^{*}}$, Olubode Olufajo ${ }^{3}$ and Israel T Agaku
}

\begin{abstract}
Background: Secondhand smoke (SHS) exposure is a well-established health hazard. To determine the effectiveness of existing smoke-free policies and adoption of smoke-free rules in South Africa, we assessed exposure to SHS from several sources among non-smoking adults during 2010.

Methods: Data were analyzed for 3,094 adults aged $\geq 16$ years who participated in the 2010 South African Social Attitudes Survey. Descriptive statistics and multivariate analyses were used to assess presence of smoke-free rules among all South Africans, and prevalence and correlates of SHS exposure at work, at home, and at hospitality venues among non-smokers.

Results: Overall, $70.6 \%$ of all South African adults had $100 \%$ smoke-free rules in their private cars, $62.5 \%$ in their homes, while $63.9 \%$ worked in places with 100\% smoke-free policies. Overall, 55.9\% of all non-smokers reported exposure to SHS from at least one source (i.e., in the home, workplace or at a hospitality venue). By specific source of exposure, $18.4 \%$ reported being exposed to SHS at work, $25.2 \%$ at home, $33.4 \%$ in a restaurant, and $32.7 \%$ at a bar. Presence of work bans on indoor smoking conferred lower likelihood of SHS exposure at work among non-smokers (adjusted odds ratio $[\mathrm{aOR}]=0.23 ; 95 \% \mathrm{Cl}$ : 0.09-0.60). Similarly, smoke-free home rules decreased the odds of being exposed to SHS at home among non-smokers ( $a \mathrm{OR}=0.16 ; 95 \% \mathrm{Cl}$ : 0.09-0.30).

Conclusion: Over half of South African adults reported SHS exposure in the home or at public places such as the workplace and at hospitality venues. This underscores the need for comprehensive smoke-free laws that prohibit smoking in all public indoor areas without exemptions.
\end{abstract}

Keywords: Smoking, Policy, Secondhand smoke, Bans, Cars, Homes, Tobacco, Cigarettes, Smoke-free, Non-smokers

\section{Background}

On April 19, 2005, South Africa became a party to the World Health Organization's (WHO) Framework Convention on Tobacco Control (FCTC) [1]. Under this international Treaty which has been ratified by 175 countries, South Africa has a legal obligation to implement and enforce policies that protect non-smokers from involuntary exposure to tobacco smoke. Article 8 of the WHO FCTC requires parties to make enhanced and sustained efforts to protect nonsmoking children and adults from secondhand

\footnotetext{
* Correspondence: Lekan.Ayo-Yusuf@ul.ac.za

'School of Health Systems and Public Health, University of Pretoria, Pretoria, South Africa

${ }^{2}$ Office of the Director, School of Oral Health Sciences, University of Limpopo MEDUNSA campus, Pretoria, South Africa

Full list of author information is available at the end of the article
}

smoke (SHS) exposure in "indoor workplaces, public transport, indoor public places, and as appropriate, other public places" [2]. Although South Africa has implemented smoke-free laws in indoor public areas, the laws currently allow designated indoor smoking areas in workplaces and other public places [3,4]. A recent airquality monitoring study in the country's capital, suggest these measures are ineffective in protecting nonsmokers from involuntary SHS exposure. In designated smoking areas of popular eateries which were assessed in the air-quality monitoring study, measured levels of respirable particulate matter $\leq 2.5$ microns in diameter (which are released from burning cigarettes) were over seven-fold higher than the WHO standard of $25 \mu \mathrm{g} / \mathrm{m}^{3}$ set for good air quality [5]. Nonetheless, recent legislative 
advances have the potential to strengthen smoke-free laws in South Africa. For example, the 2007 Amendment of the Tobacco Products Control Act No 83 of 1993 provided opportunities for more broad scale reductions in SHS exposure among vulnerable groups [3]. The new legislation prohibits smoking in private cars if a child $<12$ years is a passenger, as well as smoking within a prescribed distance of the entrance to a public place. The proposed law also regulates smoking in selected outdoor areas, with increased fines for violations of indoor smoke-free laws.

Although the new comprehensive smoke-free law is yet to be implemented and is currently opposed by the industry, evidence indicates that such smoke-free laws have a beneficial effect on the public, particularly considering that there is no safe level of exposure to SHS [6]. Not only do such comprehensive smoke-free laws protect non-smokers from involuntary SHS exposure, they also change social norms and can motivate smokers to quit [6]. In addition, such laws have the potential to raise public awareness about the dangers of tobacco smoke and can influence individuals to become more conscious about their exposure to SHS. In this regard, they may have a ripple effect in influencing individuals to voluntarily adopt smoke-free rules in their private homes, cars, and other micro-environments - areas usually out of the reach of smoke-free laws.

However, strict and consistent enforcement of smokefree laws is required if continued compliance and population support is to be expected $[7,8]$. In addition, continuous tobacco surveillance is needed to assess the effectiveness of smoke-free policies so as to provide translational science for improvements and enhancements in policy and practice. To provide an insight into South African adults' voluntary adoption of smoke-free rules in their private home and cars, and the existence of smoke-free policies in the work environment, as well as exposure of non-smokers to SHS at work, hospitality venues and private homes, this study analyzed nationally representative data of South African Adults from the 2010 South African Social Attitudes Survey (SASAS).

\section{Methods}

\section{Survey design/sample}

This secondary data analysis involved a nationally representative sample of South African adults aged $\geq 16$ years who participated in the $2010(n=3,094$, response rate $=85.8 \%)$ wave of the South African Social Attitudes Survey (SASAS). The survey samples were drawn from the master sample of the Human Sciences Research Council (HSRC). The surveys used a multi-stage probability sampling strategy with census enumeration areas as the primary sampling unit and the stratification of the enumeration areas was done by the socio-demographic domains of province, geographical sub-type and the four population groups [9].
This Study was approved by Human Sciences Research Council ethics committee.

\section{Socio-demographic characteristics}

Socio-demographic characteristics assessed included age (16-24, 25-34, 35-44, 45-54 or $\geq 55$ years); educational attainment $(<12,=12$, or $>12$ years of schooling); sex (male or female); ethnicity (self-identification as Black African, Colored (mixed ancestry), Indian/Asian, or White); marital status (never married, separated/widowed/divorced, or married); and region (urban or rural).

\section{Current tobacco smoking, exposure to, and perceptions about SHS}

Current tobacco smokers were defined as respondents who reported smoking hand-rolled or manufactured cigarettes, cigars, pipes, or water-pipes daily or on some days. Exposure to SHS at different locations including at home, work, shabeens (i.e., local informal bars), bars, or clubs, as well as at restaurants were assessed separately, with the stem question: 'In the past 30 days, about how many days would you say you were in a place where someone smoked close (no separation, but in the same area) to you?' Categorical responses were 'Never', '1-5 days' , '11-15 days', '16-20 days', or 'more than 20 days'. All responses other than 'Never' were categorized as being exposed to SHS in the respective environments assessed.

Perception about the harmfulness of SHS was assessed using the question 'In your opinion, to what extent is exposure to second-hand smoke (cigarette smoke from others) harmful to non-smokers health?' Respondents who answered 'Very harmful', or 'Somewhat harmful' were categorized as believing that SHS exposure was harmful, whereas a response of 'Not harmful' or 'Do not know/can't choose' was categorized to indicate lack of correct knowledge about the harmfulness of SHS exposure.

\section{0\% Smoke-free policies/rules}

Smoking restrictions at work, in the home and in private cars were assessed separately using the question: 'Which of the following best describes smoking at your work, home or car?' Categorical responses were provided separately for each of the three environments (work, home and cars), and were: 'Smoking is allowed', 'Smoking is generally banned with few exceptions', or 'Smoking is never allowed'. Respondents who indicated that smoking was never allowed in the respective area assessed were classified as having 100\% smoke-free environments, whereas all other responses were categorized as not having complete smoke-free policies without exemptions.

Self-rated importance of $100 \%$ smoke-free environments at home, workplaces, hospitals, cafes/restaurants, and at shabeens (informal bars), bars, or clubs were assessed separately and were respectively defined as a report of 
'Very important' or 'Somewhat important' to the question 'How important is it to you to have $100 \%$ smokefree (no smoking areas) environment in the following places?'

\section{Analyses}

All data were weighted to account for the complex survey design and yield nationally representative estimates. The proportion of adults who had $100 \%$ smoke-free policies at work, in their homes, or their cars was calculated overall, as well as by age, education, sex, ethnicity, region and current smoking status. In addition, the proportion of non-smokers who reported being exposed to SHS at work, in their homes, in a café/restaurant or at a shabeen, bar, or club was also assessed overall and further stratified by the afore-mentioned socio-demographic characteristics. Any exposure to SHS was defined as a report by a nonsmoker that they were exposed to SHS from at least one of the four environments assessed (i.e., work, home, café/ restaurant, or at a shabeen, bar or club).

To assess factors associated with exposure to SHS exposure in the various environments assessed, multivariate logistic regression analyses were performed, adjusting for age, education, sex, ethnicity, and region $(p<0.05)$. All analyses were performed with Stata 11 (StataCorp 2009, College Station, TX).

\section{Results}

Prevalence of $100 \%$ smoke-free policies at home, work, and in private cars among all South African Adults

In total, $18.1 \%(\mathrm{n}=633)$ of adults aged $\geq 16$ years were current tobacco smokers. Smoking prevalence by ethnicity was as follows: black Africans (13.8\%); Coloreds (36.3\%); whites (30.8\%); and Indians/Asians (22.1\%).

During 2010, 62.5\% of South African adults had 100\% smoke-free policies in their homes, 63.9\% worked in places with $100 \%$ smoke-free policies, and $70.6 \%$ of all adults had $100 \%$ smoke-free policies in their private cars. Variations in presence of $100 \%$ smoke-free environments were observed among population subgroups (Table 1).

There were no significant differences in the prevalence of $100 \%$ smoke-free policies in the home, workplace or private cars when stratified by age, sex, education level, residence type or marital status. However, significant within-group differences were observed by ethnicity for $100 \%$ smoke-free policies in all the environments assessed. During 2010, presence of $100 \%$ smoke-free policies in work-place was highest among Whites (67.9\%) and lowest among Colored respondents (50.5\%). Presence of 100\% smoke-free policies in the home was highest among Indian or Asian respondents in 2010 (65.4\%) and lowest among Colored respondents (47.6\%). The proportion of South African adults that had $100 \%$ smoke-free policies in their private cars in 2010 was highest among black
Africans (74.4\%) and lowest among Colored respondents (56.1\%).

Overall, the vast majority of nonsmoking South African adults perceived that smoke-free environments were important (Table 2), although this perceived importance was significantly lower for hospitality venues such as cafes/restaurants $(86.1 \%)$ or at shabeens, bars or clubs (66.2\%), compared to at work (91.2\%), home (93.1\%), or in hospitals (94.7\%) (Table 2). Virtually all (99.6\%) nonsmokers believed that SHS was harmful.

\section{Exposure to SHS at home, in the workplace and at hospitality venues among non-smokers}

Overall, 55.9\% of all non-smoking South African adults reported exposure to SHS from at least one source (i.e., in the home, workplace, café/restaurant or at a shabeen, bar, or club) during 2010. By specific source of exposure, $18.4 \%$ reported being exposed to SHS at work, $25.2 \%$ at home, $33.4 \%$ in a café/restaurant, and $32.7 \%$ at a shabeen, bar, or club (Table 3).

After adjusting for all other factors, females had significantly lower odds of being exposed to SHS at work ( $a \mathrm{OR}$ $=0.81 ; 95 \%$ CI: $0.75-0.88)$ and at home $(a \mathrm{OR}=0.73 ; 95 \%$ CI: 0.620 .87$)$ but did not differ significantly from males with respect to SHS at café/restaurants and at shabeens, bars, or clubs (Table 4). Compared to respondents aged 16-24 years, the odds of SHS exposure in a shabeen, bar, or club were significantly lower among older respondents aged $45-54$ years $(a \mathrm{OR}=0.47$; 95\% CI: 0.38-0.60). Similarly, respondents aged $\geq 55$ years had lower odds of being exposed to SHS in a café/restaurant compared to those aged $16-24$ years $(a \mathrm{OR}=0.59$; 95\% CI: 0.42-0.82).

By education, respondents with $>12$ years of secular education had lower odds of being exposed to SHS at home $(a \mathrm{OR}=0.41 ; 95 \% \mathrm{CI}$ : $0.27-0.63)$ but higher odds of being exposed to SHS at work $(a \mathrm{OR}=1.63$; $95 \% \mathrm{CI}$ : 1.13-2.37) compared to those with $<12$ years of education. Also, those with 12 years of education had higher odds of being exposed to SHS at a café/restaurant compared to those with $<12$ years of education $(a \mathrm{OR}=1.37$; 95\% CI: 1.07-1.77).

By marital status, respondents who were married had higher odds of being exposed to SHS at work compared to those were never married $(a \mathrm{OR}=1.22 ; 95 \% \mathrm{CI}: 1.03-1.45)$. Also, the odds of SHS exposure in a shabeen, bar, or club were significantly higher among respondents who were separated, widowed or divorced compared to those who were never married ( $a \mathrm{OR}=1.08$; 95\% CI: 1.02-1.14).

Whites had lower odds of being exposed to SHS at work compared to black Africans $(a \mathrm{OR}=0.78 ; 95 \% \mathrm{CI}$ : 0.65-0.94), but higher odds of being exposed to SHS at a café/restaurant compared to black Africans $(a \mathrm{OR}=1.42$; 95\% CI: 1.08-1.87), Also, the odds of SHS exposure in a shabeen, bar, or club were significantly lower among 
Table 1 Proportion of South African Adults aged $\geq 16$ years that reported having smoke-free rules at work, at home, and in their private cars, South African Social Attitudes Survey, 2010

\begin{tabular}{|c|c|c|c|c|}
\hline \multirow[t]{3}{*}{ Characteristics } & \multirow[t]{3}{*}{ Sample } & \multirow{3}{*}{$\begin{array}{l}\text { Work } \\
\%(95 \% \mathrm{Cl}) \\
(\mathrm{n}=2,553)\end{array}$} & \multirow{3}{*}{$\begin{array}{l}\text { Home } \\
\%(95 \% \mathrm{Cl}) \\
(\mathrm{n}=2,995)\end{array}$} & \multirow{3}{*}{$\begin{array}{l}\text { Car } \\
\%(95 \% \mathrm{Cl}) \\
(\mathrm{n}=2,654)\end{array}$} \\
\hline & & & & \\
\hline & & & & \\
\hline Overall & 3,112 & $63.9(59.5-68.3)$ & $62.5(60.7-64.4)$ & $70.6(65.0-76.3)$ \\
\hline \multicolumn{5}{|l|}{ Sex } \\
\hline Male & 1,783 & $63.2(61.8-64.6)$ & $61.2(58.2-64.3)$ & $69.7(63.0-76.4)$ \\
\hline Female & 1,311 & $65.0(56.9-73.1)$ & $64.5(62.5-66.5)$ & $72.1(67.1-77.2)$ \\
\hline \multicolumn{5}{|l|}{ Age, years } \\
\hline $16-24$ & 618 & $65.3(62.1-68.5)$ & $61.6(57.1-66.1)$ & $68.9(59.3-78.5)$ \\
\hline $25-34$ & 699 & $61.8(53.7-69.9)$ & $63.3(57.7-68.9)$ & $71.1(67.3-74.9)$ \\
\hline $35-44$ & 656 & $60.4(53.6-67.2)$ & $60.8(53.9-67.7)$ & $69.5(51.4-87.5)$ \\
\hline $45-54$ & 449 & $63.9(57.0-70.8)$ & $66.2(60.1-72.4)$ & $71.0(61.4-80.6)$ \\
\hline$\geq 55$ & 688 & $68.9(60.0-77.8)$ & $62.2(58.9-65.5)$ & $74.0(58.1-90.0)$ \\
\hline \multicolumn{5}{|l|}{ Education } \\
\hline$<12$ years of schooling & 1,683 & $65.0(56.9-73.1)$ & $60.6(56.1-65.0)$ & $71.5(63.1-80.0)$ \\
\hline$=12$ years of schooling & 880 & $62.6(59.5-65.7)$ & $64.3(60.3-68.3)$ & $68.8(65.3-72.4)$ \\
\hline$>12$ years of schooling & 476 & $61.9(53.6-70.3)$ & $65.8(58.5-73.1)$ & $72.7(68.5-76.9)$ \\
\hline \multicolumn{5}{|l|}{ Marital status } \\
\hline Never married & 1,337 & $63.9(59.2-68.6)$ & $63.5(57.9-69.0)$ & $71.4(67.2-75.5)$ \\
\hline Separated, widowed, or divorced & 489 & $66.6(54.2-79.0)$ & $64.5(60.9-68.1)$ & $70.9(50.0-91.8)$ \\
\hline Married & 1,204 & $62.7(55.8-69.6)$ & $60.3(56.2-64.4)$ & $69.5(54.8-84.3)$ \\
\hline \multicolumn{5}{|l|}{ Ethnicity } \\
\hline Black African & 1,763 & $65.5(62.8-68.2)$ & $65.1(59.7-70.6)$ & $74.4(70.6-78.2)$ \\
\hline Colored & 555 & $50.5(43.8-57.2)$ & $47.6(33.4-61.9)$ & $56.1(41.9-70.3)$ \\
\hline Indian or Asian & 374 & $52.6(49.8-55.4)$ & $65.4(60.7-70.0)$ & $65.2(60.5-69.8)$ \\
\hline White & 395 & $67.9(67.4-68.4)$ & $59.0(58.8-59.3)$ & $61.5(60.3-62.8)$ \\
\hline \multicolumn{5}{|l|}{ Residence type } \\
\hline Urban & 2,246 & $62.9(60.9-64.9)$ & $63.1(60.2-66.0)$ & $69.0(69.0-69.1)$ \\
\hline Rural & 866 & $65.8(61.0-70.5)$ & $61.5(58.7-64.3)$ & $73.7(68.1-79.2)$ \\
\hline \multicolumn{5}{|c|}{ Current Smoking of combustible tobacco products $^{a}$} \\
\hline Non smoker & 2,410 & $70.5(68.3-72.8)$ & $71.3(63.0-79.5)$ & $78.4(76.8-80.0)$ \\
\hline Current smoker & 633 & $36.1(25.7-46.5)$ & $25.9(22.4-29.5)$ & $37.7(31.8-43.6)$ \\
\hline
\end{tabular}

Note: $\mathrm{Cl}=$ confidence interval. Denominators for the various environments assessed included only participants whose responses indicated that they worked, had a home, or had a car in their household respectively. The proportion of missing/inapplicable responses excluded from the denominators for the respective environments included: work (17.6\%; $n=559)$; home $(3.2 \% ; n=117)$; and car $(16.4 \% ; n=458)$.

${ }^{a}$ Current smokers were respondents who reported daily or some days smoking of manufactured or hand-rolled cigarettes, cigars, pipes, or water-pipes.

Indians/Asians $(a \mathrm{OR}=0.40 ; 95 \% \mathrm{CI}: 0.24-0.65)$ as well as among Coloreds $(a \mathrm{OR}=0.57 ; 95 \% \mathrm{CI}$ : 0.34-0.96) when compared to black Africans.

\section{Effect of smoking bans in protecting non-smokers from SHS smoke}

Presence of work bans on indoor smoking conferred lower odds of exposure to SHS at work $(a \mathrm{OR}=0.23$; 95\% CI: $0.09-0.60)$. Similarly, presence of $100 \%$ smoke-free home rules decreased the odds of being exposed to SHS at home $(a \mathrm{OR}=0.16 ; 95 \%$ CI: 0.09-0.30).

\section{Discussion}

The findings from this study showed that during 2010, about two-thirds of the adult population had 100\% smoke-free policies in their homes or workplaces, while approximately 3 of every 5 had adopted smoke-free rules in their private cars. These findings are a clear indication that the majority of South African adults are not only aware of the harmful health effects of involuntary exposure to SHS, but are also taking positive actions to protect themselves from such exposure. However, our findings showed that about half (55.9\%) of non-smokers were still exposed to SHS from at least one source. This underscores 
Table 2 Proportion of non-smoking ${ }^{a}$ South African Adults aged $\geq 16$ years that reported that $100 \%$ smoke-free environments in private and public places were important to them, South African Social Attitudes Survey, 2010 ( $n=2,410)$

\begin{tabular}{|c|c|c|c|c|c|c|}
\hline \multirow[t]{2}{*}{ Characteristics } & \multirow[t]{2}{*}{ Sample } & \multirow{2}{*}{$\begin{array}{l}\text { Work } \\
\%(95 \% \mathrm{Cl})\end{array}$} & \multirow{2}{*}{$\begin{array}{l}\text { Home } \\
\%(95 \% \mathrm{Cl})\end{array}$} & \multirow{2}{*}{$\begin{array}{l}\text { Hospitals } \\
\%(95 \% \mathrm{Cl})\end{array}$} & \multirow{2}{*}{$\begin{array}{l}\text { Café/Restaurants } \\
\%(95 \% \mathrm{Cl})\end{array}$} & \multirow{2}{*}{$\begin{array}{l}\text { Shabeens (local bars) } \\
\text { Bars or Clubs } \\
\%(95 \% \mathrm{Cl})\end{array}$} \\
\hline & & & & & & \\
\hline Overall & 2,410 & $91.2(87.2-95.1)$ & $93.1(89.1-97.0)$ & $94.7(92.4-97.0)$ & $86.1(83.3-88.9)$ & $66.2(63.2-69.2)$ \\
\hline \multicolumn{7}{|l|}{ Sex } \\
\hline Male & 1,353 & $91.1(87.4-94.8)$ & $92.9(88.0-97.9)$ & 94.5 (92.1-96.9) & $85.1(81.6-88.5)$ & $65.6(63.0-68.2)$ \\
\hline Female & 1,044 & $91.4(84.8-98.0)$ & 93.5 (89.7-97.3) & $95.2(92.5-97.9)$ & $87.6(84.1-91.1)$ & $67.8(63.1-72.4)$ \\
\hline \multicolumn{7}{|l|}{ Age, years } \\
\hline $16-24$ & 496 & $91.6(85.9-97.3)$ & $92.5(88.8-96.2)$ & 94.7 (92.1-97.3) & $81.7(76.2-87.2)$ & $59.9(56.6-63.1)$ \\
\hline $25-34$ & 536 & $89.3(77.5-100.0)$ & $92.2(84.6-99.7)$ & 92.9 (86.2-99.7) & $85.8(81.5-90.1)$ & $66.9(61.3-72.6)$ \\
\hline $35-44$ & 499 & $92.3(87.8-96.7)$ & $94.1(88-100.0)$ & $96.6(94.8-98.4)$ & $87.2(82.2-92.2)$ & $64.2(57.7-70.6)$ \\
\hline $45-54$ & 339 & $92.9(89.6-96.1)$ & $96.0(92.0-100.0)$ & 97.5 (96.1-98.8) & $90.4(85.8-95.1)$ & $71.7(62.3-81.1)$ \\
\hline$\geq 55$ & 539 & $91.0(82.9-99.0)$ & $92.1(86.3-97.9)$ & 93.4 (87.9-98.9) & $89.2(83.6-94.8)$ & $73.4(70.6-76.2)$ \\
\hline \multicolumn{7}{|l|}{ Education } \\
\hline$<12$ years of schooling & 1,322 & $90.9(86.5-95.3)$ & $92.6(87.5-97.7)$ & $94.5(91.5-97.4)$ & $86.4(84.1-88.7)$ & $66.5(62.2-70.9)$ \\
\hline$=12$ years of schooling & 695 & $92.3(85.6-99.0)$ & $93.2(89.0-97.5)$ & $94.9(89.8-100.0)$ & $85.3(81.3-89.4)$ & $67.5(62.0-73.0)$ \\
\hline$>12$ years of schooling & 362 & 89.4 (85.1-93.8) & 94.4 (93.3-95.5) & $94.9(93.6-96.1)$ & 86.2 (73.9-98.5) & $60.5(44.2-76.7)$ \\
\hline \multicolumn{7}{|l|}{ Marital status } \\
\hline Never married & 1,069 & $91.4(83.4-99.4)$ & $93.1(88.4-97.8)$ & $95.1(92.6-97.7)$ & $84.8(82.0-87.6)$ & $63.0(59.4-66.7)$ \\
\hline Separated, widowed, or divorced & 384 & $91.2(83.2-99.2)$ & $93.5(86.6-100.0)$ & $93.2(86.2-100.0)$ & $86.4(82.3-90.5)$ & $66.7(56.6-76.7)$ \\
\hline Married & 920 & $90.5(82.5-98.4)$ & $92.6(87.7-97.5)$ & $94.3(90.6-98.0)$ & $87.8(81.7-93.9)$ & $70.7(66.2-75.2)$ \\
\hline \multicolumn{7}{|l|}{ Ethnicity } \\
\hline Black African & 1,484 & $91.0(85.8-96.2)$ & $93.3(89.7-97.0)$ & $94.1(90.4-97.7)$ & $86.3(83.6-89.1)$ & $65.5(60.8-70.1)$ \\
\hline Colored & 349 & $89.6(78.5-100.0)$ & $89.6(61.0-100.0)$ & $97.2(95.6-98.8)$ & $84.0(63.4-100.0)$ & $69.3(50.6-87.9)$ \\
\hline Indian or Asian & 294 & $95.1(93.8-96.4)$ & $95.6(94.4-96.7)$ & $97.4(96.7-98.1)$ & $88.3(85.3-91.4)$ & $65.9(60.4-71.4)$ \\
\hline White & 264 & $93.3(92.9-93.8)$ & $93.5(93.1-94.0)$ & $98.5(98.4-98.6)$ & $85.2(84.2-86.3)$ & $73.0(71.2-74.9)$ \\
\hline \multicolumn{7}{|l|}{ Residence type } \\
\hline Urban & 1,689 & $90.2(88.5-91.9)$ & $93.0(92.1-93.9)$ & $94.3(92.4-96.2)$ & $87.1(86.8-87.4)$ & $67.1(62.0-72.1)$ \\
\hline Rural & 721 & $92.7(87.0-98.5)$ & $93.2(83.1-100.0)$ & $95.3(91.4-99.3)$ & $84.4(79.3-89.5)$ & $64.7(60.5-69.0)$ \\
\hline
\end{tabular}

Note: $\mathrm{Cl}=$ confidence interval.

${ }^{a}$ Non-smokers were respondents who reported not smoking hand-rolled or manufactured cigarettes, cigars, pipes, or water-pipes.

the need for total bans on indoor smoking in public places with no exemptions. Such $100 \%$ smoke-free laws would not only be simpler and more consistent to enforce, but would also be more effective in reducing SHS exposure, particularly among individuals who currently work in designated smoking areas at hospitality venues. This is particularly important because, many nonsmoking employees who work in such areas (generally individuals of low socio-economic status), may be afraid to assert their right to smoke-free air at their work place because of fear of upsetting their employers [3].

The fact that virtually all non-smokers believed that SHS exposure was harmful and the vast majority indicated their support for $100 \%$ smoke-free policies in private and public areas could have some policy implications. For example, it may underscore the need for population-based educational campaigns which provide smoking cessation advice, or information on how to help a smoking friend or relative to quit. Such campaigns could also be opportunities to encourage non-smokers to be active citizens in enforcing smoke-free laws, e.g., by calling the appropriate enforcement agency in instances of violations of indoorsmoke free laws. Such concerted efforts by both individual non-smokers, and law enforcement officers may help denormalize smoking in public areas, thus encouraging smoke-free environments.

Our findings also showed some disparities in exposure to SHS among population subgroups. For example, women were significantly more likely than men to work in places with $100 \%$ smoke-free policies, which has been observed in previous research [10]. This may be due to the higher prevalence of females in certain professions where smoke-free environments are especially the norm, including nurses, child-minding, clerical staff and school 
Table 3 Prevalence of Secondhand Smoke Exposure in different environments among nonsmoking ${ }^{a}$ South African Adults aged $\geq 16$ years, South African Social Attitudes Survey $2010(n=2,410)$

\begin{tabular}{|c|c|c|c|c|c|c|}
\hline \multirow[t]{2}{*}{ Characteristic } & \multirow[t]{2}{*}{ Sample } & \multirow{2}{*}{$\begin{array}{l}\text { Work } \\
\%(95 \% \mathrm{Cl})\end{array}$} & \multirow{2}{*}{$\begin{array}{l}\text { Home } \\
\%(95 \% \mathrm{Cl})\end{array}$} & \multirow{2}{*}{$\begin{array}{l}\text { Café or Restaurants } \\
\%(95 \% \mathrm{Cl})\end{array}$} & \multirow{2}{*}{$\begin{array}{l}\text { Shabeens (local bars), } \\
\text { Bars or Clubs } \\
\%(95 \% \mathrm{Cl})\end{array}$} & \multirow{2}{*}{$\begin{array}{l}\text { Any exposure }^{b} \\
\%(95 \% \mathrm{Cl})\end{array}$} \\
\hline & & & & & & \\
\hline Overall & 2,410 & $18.4(15.7-21.2)$ & $25.2(15.7-34.6)$ & $33.4(25.4-41.4)$ & $32.7(25.7-39.8)$ & $55.9(52.3-59.4)$ \\
\hline \multicolumn{7}{|l|}{ Sex } \\
\hline Male & 1,353 & $20.7(19.4-22.0)$ & $27.0(19.4-34.7)$ & $34.7(28.9-40.5)$ & $34.2(27.7-40.7)$ & $58.2(54.1-62.3)$ \\
\hline Female & 1,044 & $15.1(10.6-19.5)$ & $22.5(8.4-36.5)$ & $31.3(21.3-41.3)$ & $30.3(19.6-40.9)$ & $52.7(47.8-57.6)$ \\
\hline \multicolumn{7}{|l|}{ Age, years } \\
\hline $16-24$ & 496 & $11.1(0.9-21.3)$ & $25.3(19.8-30.9)$ & $34.7(25.8-43.6)$ & $36.3(19.8-52.9)$ & $60.5(54.5-66.6)$ \\
\hline $25-34$ & 536 & $26.0(23.0-29.1)$ & $31.2(13.6-48.9)$ & $36.2(31.8-40.5)$ & $44.2(28.9-59.5)$ & $62.0(55.6-68.4)$ \\
\hline $35-44$ & 499 & $24.4(14.3-34.6)$ & $23.2(8.0-38.4)$ & $32.6(24.5-40.7)$ & $27.7(22.7-32.7)$ & $52.7(46.3-59.2)$ \\
\hline $45-54$ & 339 & $20.2(11.2-29.1)$ & $22.0(18.0-25.9)$ & $35.5(15.3-55.7)$ & $26.3(13.7-38.8)$ & $53.6(46.0-61.1)$ \\
\hline$\geq 55$ & 539 & $10.8(7.7-13.9)$ & $20.0(3.3-36.7)$ & $26.6(12.0-41.2)$ & $19.4(15.0-23.8)$ & $43.9(36.8-51.0)$ \\
\hline \multicolumn{7}{|l|}{ Education } \\
\hline$<12$ years of schooling & 1,322 & $14.1(7.9-20.2)$ & $28.0(21.0-34.9)$ & $28.1(23.7-32.6)$ & $28.5(20.7-36.2)$ & $53.0(48.3-57.7)$ \\
\hline$=12$ years of schooling & 695 & $23.1(14.2-31.9)$ & $24.8(10.2-39.4)$ & $39.4(36.9-42.0)$ & $38.4(28.0-48.8)$ & $61.2(55.4-67.1)$ \\
\hline$>12$ years of schooling & 362 & $25.4(19.7-31.0)$ & $15.6(13.5-17.7)$ & $40.8(22.6-59.1)$ & $37.3(27.7-46.9)$ & $55.7(48.7-62.6)$ \\
\hline \multicolumn{7}{|l|}{ Marital status } \\
\hline Never married & 1,069 & $17.2(15.3-19.1)$ & $26.7(16.6-36.8)$ & $33.4(30.0-36.7)$ & $36.0(27.9-44.1)$ & $58.1(53.5-62.7)$ \\
\hline Separated, widowed, or divorced & 384 & $13.8(0.0-29.8)$ & $23.1(8.3-38.0)$ & $29.2(7.2-51.2)$ & $24.2(17.8-30.6)$ & $46.3(40.2-56.4)$ \\
\hline Married & 920 & $22.5(19.8-25.2)$ & $24.1(14.3-33.9)$ & $34.8(22.6-47.0)$ & $29.5(20.6-38.3)$ & $54.3(49.3-59.2)$ \\
\hline \multicolumn{7}{|l|}{ Ethnicity } \\
\hline Black African & 1,484 & $18.2(15.2-21.2)$ & $26.3(17.7-34.9)$ & $32.0(26.7-37.4)$ & $34.0(23.7-44.3)$ & $55.8(51.6-60.1)$ \\
\hline Colored & 349 & $23.4(7.5-39.3)$ & $30.1(17.1-43.1)$ & $33.4(29.5-37.3)$ & $23.4(15.1-31.7)$ & $56.5(48.5-64.6)$ \\
\hline Indian or Asian & 294 & $19.8(15.4-24.1)$ & $13.0(10.7-15.2)$ & $36.7(30.2-43.1)$ & $24.8(20.5-29.2)$ & $55.3(46.4-64.1)$ \\
\hline White & 264 & $16.7(15.4-17.9)$ & $15.7(14.5-16.8)$ & $44.8(43.1-46.5)$ & $28.3(26.2-30.5)$ & $55.6(48.3-62.8)$ \\
\hline \multicolumn{7}{|l|}{ Residence type } \\
\hline Urban & 1,689 & $18.9(16.6-21.2)$ & $23.3(13.0-33.6)$ & $35.9(31.6-40.2)$ & $35.2(27.2-43.1)$ & $57.3(53.4-61.3)$ \\
\hline Rural & 721 & $17.7(15.0-20.4)$ & $28.2(27.7-28.7)$ & $29.4(27.6-31.1)$ & $28.8(26.6-31.1)$ & $53.4(46.6-60.3)$ \\
\hline
\end{tabular}

Note: $\mathrm{Cl}=$ confidence interval. Denominators for the various environments assessed included only participants whose responses indicated that they worked, had a home, had a car in their household, or that they went to cafes/restaurants; or to shabeens, bars or clubs, respectively. The proportion of missing/inapplicable responses excluded from the denominators for the respective environments included: work $(16.1 \% ; n=380) ;$ home $(2.9 \% ; n=69) ;$ cafes/restaurants $(6.3 \%$; $n=134)$; and shabeens, bars or clubs $(9.8 \% ; n=254)$,

${ }^{a}$ Non-smokers were respondents who reported not smoking hand-rolled or manufactured cigarettes, cigars, pipes, or water-pipes.

${ }^{b}$ Respondents who reported being exposed to secondhand smoke in at least one of the following: the work, home, café/restaurants, or bars, shabeens, or clubs.

teachers. There is also evidence that white-collar workers are twice as likely to be covered by smoke-free policies as blue-collar workers and women form a higher proportion of the population of white-collar workers compared to blue-collar workers $[10,11]$. The fact that the majority of those who self-identified as Coloreds were permissive of smoking in their homes may be related to the fact that this population group also has the highest smoking prevalence (36.3\% vs. national average of $18.1 \%$ ) in South Africa, and smoking may thus have become a norm. Similarly, the fact that the prevalence of smoke-free policies was consistently higher among nonsmokers than smokers in all environments could be a result of the tendency of smokers to continue smoking in such environments with only partial bans on indoor smoking, which could undermine efforts to denormalize smoking [12-14].

The prevalence of exposure to SHS at hospitality venues during 2010 among non-smokers was higher than exposure at workplaces, homes and cars. The proportion of South African non-smokers who were exposed to SHS at a café/restaurant (33.4\%) was similar to exposure at a bar, shabeen (local bar) or nightclub (32.7\%). This may reflect the laxity in the implementation of smoke-free policies in such venues possibly due to commercial interests of business owners and less government involvement in the enforcement of these polices in such locations. This underscores the need for enhanced and sustained efforts to further reduce SHS exposure among all sub-population groups through stronger enforcement of smoke-free 
Table 4 Adjusted correlates of secondhand smoke exposure in different environments among nonsmoking ${ }^{a}$ South African Adults aged $\geq 16$ years, South African Social Attitudes Survey 2010

\begin{tabular}{|c|c|c|c|c|c|c|}
\hline \multirow[t]{2}{*}{ Characteristics } & \multirow[t]{2}{*}{ Category } & Work & Home & Café/Restaurant & $\begin{array}{l}\text { Shabeen, (local bars), } \\
\text { Bar or Club }\end{array}$ & $\begin{array}{l}\text { Any secondhand } \\
\text { smoke exposure }\end{array}$ \\
\hline & & aOR $(95 \% \mathrm{Cl})$ & aOR $(95 \% \mathrm{Cl})$ & aOR $(95 \% \mathrm{Cl})$ & aOR $(95 \% \mathrm{Cl})$ & aOR $(95 \% \mathrm{Cl})$ \\
\hline \multirow[t]{2}{*}{ Sex } & \multicolumn{6}{|l|}{ Male (Referent) } \\
\hline & Female & $0.81(0.75-0.88)^{*}$ & $0.73(0.62-0.87)^{*}$ & $0.95(0.72-1.25)$ & $0.78(0.47-1.28)$ & $0.74(0.63-0.87)^{*}$ \\
\hline \multirow[t]{5}{*}{ Age, years } & \multicolumn{6}{|l|}{ 16-24 (Referent) } \\
\hline & $25-34$ & $2.23(0.59-8.47)$ & $1.43(0.56-3.67)$ & $1.02(0.56-1.85)$ & $1.04(0.37-2.92)$ & $1.18(0.62-2.24)$ \\
\hline & $35-44$ & $2.06(0.39-10.82)$ & $0.83(0.23-2.94)$ & $0.73(0.41-1.29)$ & $0.51(0.17-1.49)$ & $0.77(0.35-1.66)$ \\
\hline & $45-54$ & $1.72(0.52-5.65)$ & $0.77(0.26-2.27)$ & $0.87(0.72-1.05)$ & $0.47(0.38-0.6)^{*}$ & $0.79(0.55-1.12)$ \\
\hline & $\geq 55$ & $0.88(0.21-3.79)$ & $0.66(0.15-2.85)$ & $0.59(0.42-0.82)^{*}$ & $0.34(0.1-1.21)$ & $0.56(0.17-1.79)$ \\
\hline \multirow[t]{3}{*}{ Education } & \multicolumn{6}{|l|}{$\begin{array}{l}<12 \text { years of schooling } \\
\text { (Referent) }\end{array}$} \\
\hline & $=12$ years of schooling & $1.60(0.64-3.97)$ & $0.67(0.34-1.31)$ & $1.37(1.07-1.77)^{*}$ & $1.29(0.94-1.76)$ & $1.33(1.06-1.67)^{*}$ \\
\hline & $>12$ years of schooling & $1.63(1.13-2.37)^{*}$ & $0.41(0.27-0.63)^{*}$ & $1.16(0.49-2.79)$ & $1.23(0.67-2.23)$ & $1.22(0.68-2.2)$ \\
\hline \multirow[t]{3}{*}{ Marital status } & \multicolumn{6}{|l|}{ Never married (Referent) } \\
\hline & $\begin{array}{l}\text { Separated, widowed, } \\
\text { or divorced }\end{array}$ & $0.93(0.24-3.70)$ & $1.21(0.77-1.89)$ & $1.20(0.96-1.49)$ & $1.08(1.02-1.14)^{*}$ & $1.12(0.51-2.44)$ \\
\hline & Married & $1.22(1.03-1.45)^{*}$ & $0.98(0.45-2.16)$ & $1.14(0.91-1.42)$ & $1.13(0.75-1.69)$ & $1.13(0.93-1.36)$ \\
\hline \multirow[t]{4}{*}{ Ethnicity } & \multicolumn{6}{|l|}{ Black African (Referent) } \\
\hline & Colored & $1.45(0.60-3.52)$ & $1.53(0.91-2.55)$ & $1.10(0.97-1.25)$ & $0.57(0.34-0.96)^{*}$ & $0.85(0.49-1.48)$ \\
\hline & Indian or Asian & $0.78(0.52-1.17)$ & $0.85(0.44-1.64)$ & $0.75(0.58-0.98)^{*}$ & $0.4(0.24-0.65)^{*}$ & $0.85(0.68-1.06)$ \\
\hline & White & $0.78(0.65-0.94)^{*}$ & $0.84(0.41-1.71)$ & $1.42(1.08-1.87)^{*}$ & $0.65(0.42-1)$ & $0.8(0.62-1.04)$ \\
\hline \multirow[t]{2}{*}{ Residence type } & \multicolumn{6}{|l|}{ Urban (Referent) } \\
\hline & Rural & $1.08(0.80-1.46)$ & $1.16(0.78-1.73)$ & $0.76(0.71-0.80)^{*}$ & $0.62(0.47-0.81)^{*}$ & $0.79(0.65-0.95)^{*}$ \\
\hline
\end{tabular}

Note: Denominators for the various environments assessed included only participants whose responses indicated that they worked, had a home, had a car in their household, or that they went to cafes/restaurants; or to shabeens, bars or clubs, respectively. The proportion of missing/inapplicable responses excluded from the denominators for the respective environments included: work $(16.1 \% ; n=380)$; home $(2.9 \% ; n=69)$; cafes/restaurants $(6.3 \%$; $n=134)$; and shabeens, bars or clubs $(9.8 \% ; n=254)$,

${ }^{a}$ Non-smokers were respondents who reported not smoking hand-rolled or manufactured cigarettes, cigars, pipes, or water-pipes. $a O R=$ adjusted odds ratio; $\mathrm{Cl}=$ confidence interval.

${ }^{\mathrm{b}}$ Respondents who reported being exposed to secondhand smoke in at least one of the following: the work, home, restaurants, or bars.

*Statistically significant at $p<0.05$.

policies coupled with intensified population-based interventions aimed at reducing smoking prevalence and intensity among current smokers.

This study is the first to assess the implementation of smoke-free policies at work-places, and voluntary adoption of smoke-free rules in private environments such as the home and in cars, using a nationally representative sample of South African adults. Nonetheless, the study has some limitations. First, SHS exposure was selfreported and may have been subject to misreporting. However, recall was limited to the past 30 days, which is a relatively short period. Second, it is possible for respondents to have misclassified the presence of smokefree rules in their homes or cars (e.g., indicating they had $100 \%$ smoke-free rules when such rules did not exist), possibly because of perceived social desirability of the provided responses. Finally, these data may not be generalizable to military or other institutionalized personnel who were not included in the survey, and who may have higher smoking prevalence rates. Despite these limitations, this study underscores the need for comprehensive smoke-free laws in public places to protect non-smoking adults and children from involuntary exposure to SHS.

\section{Conclusion}

Despite the fact that the vast majority of non-smoking South African adults knew about the harmfulness of SHS exposure, with over two-thirds having implemented smoke-free rules in their cars and homes, over half still reported SHS exposure from several sources, particularly from public areas. This underscores the need for comprehensive smoke-free laws that prohibit smoking in all indoor areas without exemptions. In addition, strong enforcement of such laws may help increase compliance and denormalize smoking.

\section{Competing interests}

The authors declare that they have no competing interests. 


\section{Authors' contributions}

OA-AY was involved in acquisition of the data used for the study, conceiving the study design, interpreting the results of the analysis, and making substantial contributions to the drafting of the manuscript. $O O$ searched relevant literature, made substantial contributions to the presentation of the data, and participated in drafting the final manuscript. ITA contributed to the design of the study, carried out the analysis of the data, and drafted the initial manuscript. All authors read and approved the final manuscript.

\section{Authors' information}

OAA is a public health practitioner and holds the position of Professor and Director, at the School of Oral Health Sciences at the University of Limpopo Medunsa Campus. OAA is also an Extraordinary Professor in the School of Health Systems and Public Health at the University of Pretoria. OO is MPH student at the Harvard School of Public Health. ITA initiated the reported research while affiliated with the Center for Global Tobacco Control at Harvard University. He is currently affiliated with the Centers for Disease Control and Prevention's Office on Smoking and Health. The research in this report was completed and submitted outside of the official duties of his current position and does not reflect the official policies or positions of the Centers for Disease Control and Prevention.

\section{Acknowledgments}

This report was supported by a grant from the American Cancer Society (Grant contract\# NHINTLTAA01). The authors are grateful to the staff of the South African Human Sciences Research Council for logistic support in data collection.

\section{Author details}

${ }^{1}$ School of Health Systems and Public Health, University of Pretoria, Pretoria, South Africa. ${ }^{2}$ Office of the Director, School of Oral Health Sciences, University of Limpopo MEDUNSA campus, Pretoria, South Africa. ${ }^{3}$ Department of Epidemiology, Harvard School of Public Health, 677 Huntington Avenue, Boston, MA 02115, USA. ${ }^{4}$ Center for Global Tobacco Control, Department of Social and Behavioral Sciences, Harvard School of Public Health, 677 Huntington Avenue, Boston, MA 02115, USA.

Received: 29 January 2014 Accepted: 4 June 2014 Published: 10 June 2014

\section{References}

1. World Health Organization: Parties to the WHO Framework Convention on Tobacco Control. http://www.who.int/fctc/signatories_parties/en/.

2. World Health Organization: WHO Framework Convention on Tobacco Control. http://whqlibdoc.who.int/publications/2003/9241591013.pdf.

3. South African National Department of Health: Tobacco Control in South Africa- The Background. www.who.int/entity/fctc/implementation/ South_Africa_article8.ppt.

4. Campaign for Tobacco-Free Kids: Tobacco Control Laws. http://www.tobaccocontrollaws.org/legislation/country/south-africa/summary.

5. Ayo-Yusuf OA: Tobacco smoke pollution in the 'non-smoking' sections of selected popular restaurants in Pretoria, South Africa. Tobacco Control. 2014, 23(3):193-4. doi:10.1136/tobaccocontrol-2012-050738.

6. US Department of Health and Human Services: The health consequences of involuntary exposure to tobacco smoke: a report of the Surgeon General. http://www.surgeongeneral.gov/library/secondhandsmoke/report/ fullreport.pdf.

7. Vardavas Cl, Agaku I, Patelarou E, Anagnostopoulos N, Nakou C, Dramba V, Giourgouli G, Argyropoulou P, Antoniadis A, Gourgoulianis K, Ourda D, Lazuras L, Bertic M, Lionis C, Connolly G, Behrakis P, on behalf of the Hellenic Air Monitoring Study Investigators: Ashtrays and Signage as Determinants of a Smoke-Free Legislation's Success. PLoS One 2013, 8:e72945. doi:10.1371/journal.pone.0072945.

8. Vardavas Cl, Kondilis B, Travers MJ, Petsetaki E, Tountas Y, Kafatos AG: Environmental tobacco smoke in hospitality venues in Greece. BMC Public Health 1997, 7:302. doi: 10.1186/1471-2458-7-302

9. Human Sciences Research Council: South African Social Attitudes Survey (SASAS). http://www.hsrc.ac.za/en/departments/sasas.

10. Sweeney CT, Shopland DR, Hartman AM, Gibson JT, Anderson CM, Gower KB, Burns DM: Sex differences in workplace smoking policies: results from the current population survey. Am Med Wom Assoc 2000, 55(5):311-5.
11. Gerlach KK, Shopland DR, Hartman AM, Gibson JT, Pechacek TF: Workplace smoking policies in the United States: results from a national survey of more than 100,000 workers. Tobacco control 1997, 6(3):199-206.

12. Nagelhout GE, de Vries H, Boudreau C, Allwright $\mathrm{S}$, McNeill A, van den Putte B, Fong GT, Willemsen MC: Comparative impact of smoke-free legislation on smoking cessation in three European countries. Eur J Publ Health 2012, 22(suppl 1):4-9.

13. Pieroni L, Chiavarini M, Minelli L, Salmasi L: The role of anti-smoking legislation on cigarette and alcohol consumption habits in Italy. Health Policy 2013, 111:116-126.

14. Chapman S, Borland R, Scollo M, Brownson RC, Dominello A, Woodward S: The impact of smoke-free workplaces on declining cigarette consumption in Australia and the United States. Am J Publ Health 1999, 89(7):1018-23.

doi:10.1186/1471-2458-14-580

Cite this article as: Ayo-Yusuf et al:: Exposure to secondhand smoke and voluntary adoption of smoke-free home and car rules among non-smoking South African adults. BMC Public Health 2014 14:580.

\section{Submit your next manuscript to BioMed Central and take full advantage of:}

- Convenient online submission

- Thorough peer review

- No space constraints or color figure charges

- Immediate publication on acceptance

- Inclusion in PubMed, CAS, Scopus and Google Scholar

- Research which is freely available for redistribution

Submit your manuscript at www.biomedcentral.com/submit
C BioMed Central 